\title{
Disruption of hyaluronan synthase-2 abrogates normal cardiac morphogenesis and hyaluronan-mediated transformation of epithelium to mesenchyme
}

\author{
Todd D. Camenisch, ${ }^{1}$ Andrew P. Spicer, ${ }^{1}$ Tammy Brehm-Gibson, ${ }^{1}$ Jennifer Biesterfeldt, ${ }^{1}$ \\ Mary Lou Augustine, ${ }^{1}$ Anthony Calabro, Jr., ${ }^{2}$ Steven Kubalak, ${ }^{3}$ Scott E. Klewer, ${ }^{4}$ \\ and John A. McDonald ${ }^{1}$
}

${ }^{1}$ Samuel C. Johnson Medical Research Center, Mayo Clinic Scottsdale, Scottsdale, Arizona, USA ${ }^{2}$ Department of Bioengineering, The Cleveland Clinic, Cleveland, Ohio, USA

${ }^{3}$ Department of Cell Biology and Anatomy, Medical University of South Carolina, Charleston, South Carolina, USA

${ }^{4}$ Department of Pediatrics, University of Arizona School of Medicine, Tucson, Arizona, USA

Address correspondence to: John A. McDonald, Samuel C. Johnson Medical Research Center, Mayo Clinic Scottsdale, 13400 East Shea Boulevard, Scottsdale, Arizona 85259, USA.

Phone: (480) 301-8859; Fax: (480) 301-7017; E-mail: mcdonald.john@mayo.edu.

Andrew P. Spicer's present address is: Rowe Program in Genetics, Department of Biological Chemistry, University of California, Davis, California, USA.

Todd D. Camenisch and Andrew P. Spicer contributed equally to this work.

Received for publication May 10, 2000, and accepted in revised form June 22, 2000.

\begin{abstract}
We identified hyaluronan synthase-2 (Has2) as a likely source of hyaluronan (HA) during embryonic development, and we used gene targeting to study its function in vivo. Has2 $2^{-/}$embryos lack HA, exhibit severe cardiac and vascular abnormalities, and die during midgestation (E9.5-10). Heart explants from Has2 $2^{-/}$embryos lack the characteristic transformation of cardiac endothelial cells into mesenchyme, an essential developmental event that depends on receptor-mediated intracellular signaling. This defect is reproduced by expression of a dominant-negative Ras in wild-type heart explants, and is reversed in Has $2^{-/-}$explants by gene rescue, by administering exogenous HA, or by expressing activated Ras. Conversely, transformation in Has2 $2^{--}$explants mediated by exogenous HA is inhibited by dominant-negative Ras. Collectively, our results demonstrate the importance of HA in mammalian embryogenesis and the pivotal role of Has2 during mammalian development. They also reveal a previously unrecognized pathway for cell migration and invasion that is HA-dependent and involves Ras activation.
\end{abstract}

J. Clin. Invest. 106:349-360 (2000).

\section{Introduction}

Hyaluronan, or hyaluronic acid (HA) is a linear, highmolecular-weight (mega-Dalton) polymer comprised of repeating disaccharide units of $(\beta 1 \rightarrow 3) \mathrm{D}$-glucuronate$(\beta 1 \rightarrow 4) N$-acetyl-D-glucosamine. HA is synthesized by integral plasma membrane glycosyltransferases and is exported directly into the extracellular space $(1,2)$. Although HA is chemically homogeneous, there are three distinct mammalian HA synthases (designated Has1, Has2, and Has3), encoded by related but nonlinked genes (3-9). Each synthase has distinct catalytic properties, and the distribution and abundance of each varies during development of the mouse $(6,10)$. These observations suggest that the different Has enzymes play distinct roles.

HA binds salt and water, expanding the extracellular space (11-14). HA is especially prominent at sites where cell migration occurs, such as pathways of neural crest cell migration and in the developing cardiovascular system. In vivo, HA interacts with other extracellular matrix molecules, typically via an HA-binding domain called the link module (15). These interactions create a supramolecular architecture of the extracellular matrix, i.e., the composite matrix network of HA, link protein, and aggrecan that plays a critical role in load-bearing articular cartilage (16-18).

In addition to its important physical properties, the overexpression of Has genes results in increased anchorage-independent growth and metastasis of transformed cells $(19,20)$, suggesting a link between HA and transformation. HA is also implicated in receptor-mediated cell adhesion and intracellular signaling $(21,22)$. Taken together, such observations suggest that HA plays a vital role in diverse cellular events, including cell migration, tissue remodeling, and metastasis. However, the near-ubiquitous distribution of HA in vivo, the biological activity of HA fragments released by degradative enzymes (23), and the inability to inhibit HA synthesis in vivo have hindered definitive analysis of the physiological roles of HA. Accordingly, we used a genetic approach to investigate the roles of HA in vivo and to identify the HA synthase that is critical during embryogenesis.

Expression of Has2 appeared to correlate with expansion of cardiac cushion tissue and subsequent transformation of endocardial cells into mesenchyme. The tar- 
geted deletion of the Has2 gene results in embryonic death at approximately E9.5, with extensive abnormalities of the developing cardiovascular system. HA is virtually absent in $\mathrm{Has}^{-/-}$E9.5 embryos, demonstrating that Has 2 is the principal source of HA during initial organogenesis in the mouse. Interestingly, the Has2 $2^{--}$ embryo closely resembles that of heart defect $(h d f)$ mice lacking the HA-binding proteoglycan versican, showing that a composite matrix requiring HA and versican is essential for forming cardiac jelly to support cushion morphogenesis and subsequent cardiac development. Our studies also reveal a striking role for HA in cell migration and transformation. The use of a well-established explant system revealed absent cell migration and epithelium-to-mesenchyme transformation in the atrioventricular (AV) canal from Has $2^{-/-}$embryos. Normal transformation is rescued by Has 2 cDNA or the addition of purified HA. The requirement for $\mathrm{HA}$ in endothelial migration and transformation is abrogated by the expression of constitutively active H-Ras, and rescue by HA is inhibited by dominant-negative H-Ras. Thus, HA plays two complementary roles in development: expansion of the extracellular space, providing a hydrated matrix for cell migration; and stimulation of an invasive phenotype by cardiac endothelial cells.

\section{Methods}

In situ hybridization. In situ hybridization was performed using a full-length Has2 cDNA riboprobe (9) as described (63). To detect versican mRNA we used a 348bp fragment spanning the boundary between exons 6 and 8, detecting the VI splice form. Embryos were fixed in RNase-free $4 \%$ paraformaldehyde (PFA) and then embedded in paraffin. Serial sections were cut and deparaffinized. Riboprobes were labeled with ${ }^{35}$ S-UTP (NEN Life Science Products Inc., Boston, Massachusetts, USA) using T3 or T7 polymerase (Amersham Pharmacia Biotech, Piscataway, New Jersey, USA). Sections were then hybridized with the indicated probes in $0.02 \%$ Ficoll $400,0.02 \%$ polyvinylpyrrolidone, $0.1 \% \mathrm{BSA}, 100 \mu \mathrm{g} / \mathrm{mL}$ denatured salmon-sperm DNA, $100 \mu \mathrm{g} / \mathrm{mL}$ yeast RNA, and $10 \%$ dextran sulfate at $50^{\circ} \mathrm{C}$ for 16 hours. Hybridized sections were rinsed first in a formamide wash buffer for 30 minutes at $50^{\circ} \mathrm{C}$, then in $0.5 \times \mathrm{SSC}$ for 30 minutes at $25^{\circ} \mathrm{C}$. Unhybridized probe was removed by digestion with RNase A, followed by two 1-hour washes in $0.1 \times \mathrm{SSC}$ at $65^{\circ} \mathrm{C}$. The sections were dehydrated, and autoradiography was performed using Kodak NTB2 emulsion, Kodak Developer D-19, and Rapid Fix (Eastman Kodak Co., Rochester, New York, USA).

Histology. Embryos were fixed in 4\% PFA alone or 4\% PFA with $0.5 \%$ cetylpyridinium chloride (17), and then stained with hematoxylin and eosin or acidic alcian blue. HA was detected with $4 \mu \mathrm{g} / \mathrm{mL}$ of biotinylated HAbinding (b-PG) domains isolated from bovine nasal cartilage (64) (generously provided by Charles Underhill, Georgetown University Medical School, Washington, DC, USA). The b-PG was detected using streptavidinconjugated horseradish peroxidase and 3,3'- diaminobenzidine (DAB). Incubating b-PG with 0.1 $\mathrm{mg} / \mathrm{mL}$ HA for 1 hour at room temperature before use abolished staining, demonstrating specificity for HA.

Whole-mount immunohistochemistry. Embryos were fixed in $4 \% \mathrm{PFA}$ overnight at $4^{\circ} \mathrm{C}$, dehydrated into methanol $\left(25^{\circ} \mathrm{C}\right)$, and incubated in $5 \% \mathrm{H}_{2} \mathrm{O}_{2}$ and $95 \%$ methanol at $25^{\circ} \mathrm{C}$ for 5 hours. Embryos were rehydrated and placed in a solution of $3 \%$ nonfat milk, $0.1 \%$ Triton X-100, and PBS (PBSMT) at $25^{\circ} \mathrm{C}$ for 2 hours with one change. Embryos were incubated with $10 \mu \mathrm{g} / \mathrm{mL}$ anti-mouse CD31 (platelet endothelial-cell adhesion molecule, or PECAM) (PharMingen, San Diego, California, USA) in PBSMT overnight at $4^{\circ} \mathrm{C}$. They were then washed with PBSMT five times, and incubated with a 1:100 dilution of goat anti-rat IgG-horseradish peroxidase conjugate (Kirkegaard and Perry Laboratories Inc., Gaithersburg, Maryland, USA) in PBSMT at $4^{\circ} \mathrm{C}$ overnight. Next, the embryos were washed in PBSMT six times and rinsed in PBS containing $0.1 \%$ Triton X-100 for 20 minutes, followed by the addition of $0.3 \mathrm{mg} / \mathrm{mL}$ of DAB substrate (Sigma Chemical Co., St. Louis, Missouri, USA) in PBS containing $0.5 \% \mathrm{NiCl}_{2}, 0.1 \%$ Triton-X100 and $0.2 \% \mathrm{BSA}$. This was allowed to stand for 5 minutes at room temperature. Finally, embryos were washed in PBS containing $0.1 \%$ Triton-X100 and $0.2 \%$ BSA, postfixed in PFAglutaraldehyde, and transferred into 50\% glycerol in PBS and then $70 \%$ glycerol in PBS. Images were taken with a Leica M3Z inverted microscope.

Microdissection and scanning electron microscopy. Embryos were fixed with $2 \%$ glutaraldehyde and $1 \%$ PFA in $1 \%$ cacodylate buffer. The chest wall and the pericardium were dissected free, and the embryos were postfixed in $2 \% \mathrm{OsO}_{4}$, washed in $0.2 \mathrm{M}$ cacodylate buffer ( $\mathrm{pH} 7.3$ ), and then dehydrated through graded ethanols and critical-point dried (Tousimis Samdri-PVT-3B; Tousimis, Rockville, Maryland, USA). Specimens were mounted on scanning electron microscopy tubes and ion spattered with 300-nm gold (SEM Coating System; Bio-Rad Laboratories Inc., Hercules, California, USA). The specimens were examined in a JEOL JSM-6300V scanning electron microscope (JEOL U.S.A., Boston, Massachusetts, USA). For section-directed analysis, embryos were processed essentially as described (65).

Gene targeting. The Has2-targeting vector was created by ligating a 1.6-kb HindIII fragment (short arm of homology) containing exon 3 into the unique HindIII site at the $3^{\prime}$ end of the PGK-Neo cassette (EcoRI-HindIII fragment of pGK-1) in pBluescript. A 4-kb EcoRI fragment (long arm of homology) extending from a site 60 codons into exon 4 to a site immediately downstream of the $3^{\prime}$ untranslated region was ligated into the EcoRI site located at the $5^{\prime}$ end of the PGK-Neo cassette. A 2.2-kb NotI cassette containing the diphtheria toxin A chain was added to the ends of both arms of homology to facilitate negative selection. The plasmid was linearized with SacII and electroporated into GK129 ES cells (25). Cells were selected with G418 (66). G418-resistant clones were screened by PCR with primers for the PGKNeo cassette and the sequence flanking the1.6-kb 
HindIII short arm of homology (Figure 2). Southern analysis of BamHI and EcoRI genomic DNA digests used probes from the 5' (box 1 in Figure 2a) and 3' flanking regions (box 2 in Figure 2a). Two correctly targeted ES cell clones were expanded, microinjected into C57BL/6J blastocysts, and transferred to the uteri of pseudopregnant CD1 female mice. Chimeric animals were backcrossed onto a C57BL/6J background to screen for germline transmission. Tail biopsy or yolk sac genomic DNAs were amplified by PCR with primers specific for the wild-type allele and the targeted allele (Has2 wildtype 5': GGCCTGCCAGTCTTATTTTGGCTG; Has2 wildtype 3': GTAGAAGAGCTGGATGACTGTGGC; targeted allele: PGK-Neo 5': GAGGCCACTTGTGTAGCGCCAAG; and Has2 wild-type $3^{\prime}$ ).

$A V$ canal endocardial cushion morphogenesis assay. The AV canal ("explant") from E9.5 wild-type and mutant embryos was placed on a type I collagen gel (rat tail collagen, Sigma Chemical Co.) (32) and grown in a culture medium of $0.1 \mathrm{~mL}$ of Medium 199 supplemented with 1\% FBS (HyClone Laboratories, Logan, Utah, USA), $100 \mathrm{U} / \mathrm{mL}$ penicillin, $100 \mu \mathrm{g} / \mathrm{mL}$ streptomycin, and $0.1 \%$ each insulin, transferrin, and selenium (GIBCO BRL, Grand Island, New York, USA) in fourwell microculture dishes (Nalge Nunc International, Naperville, Illinois, USA) at $37^{\circ} \mathrm{C}$ in $5 \% \mathrm{CO}_{2}$ for $48-72$ hours. Explants were supplemented with HA, either by adding to the medium $0.75 \mathrm{mg} / \mathrm{mL}$ of $\mathrm{HA}$ (mean mol wt: 757,000; Calbiochem-Novabiochem Co., San Diego, California, USA) dialyzed against serum-free culture medium, or by incorporating $0.25 \mathrm{mg} / \mathrm{mL} \mathrm{HA}$ into the collagen gel. (Boiling the HA before use had no effect upon cell migration or invasion.) Independent experiments were repeated a minimum of five times. Transformation of endothelium to mesenchyme and invasion into the collagen gel was scored from 0 to 4 (67). A score of 0 represents AV explants with no cell migration. With migration and transformation present, 1 represents $1-20$ cells; $2,21-50$ cells; $3,51-99$ cells; and 4 represents $\geq 100$ cells. Scoring was performed by observers who did not know the experimental conditions. Interobserver error was less than 0.5 units. Statistical analysis used the Wilcoxon's rank sum test. Extensive invasion of the collagen gel in Has $2^{-/-}$rescued explants was confirmed by $3 \mathrm{D}$ reconstruction of laser scanning confocal microscopy of explants (data not shown).

$\mathrm{AV}$ canal explants were transfected using inactivated adenovirus (68). Plasmids encoding cytomegalovirusdriven, constitutively active H-Ras (Q61L) and dominant-negative H-Ras (S17N) were purchased from Upstate Biotechnology Inc. (Lake Placid, New York, USA). After overnight incubation to allow attachment, each explant was incubated with $4.2 \times 10^{7}$ viral particles mixed with $1 \mu \mathrm{g}$ of plasmid DNA in Opti-MEM (GIBCO BRL) for 2.5 hours at $37^{\circ} \mathrm{C}$. Medium was aspirated and replaced with culture medium. AV explants were cultured for an additional 48 hours and then assessed as indicated.
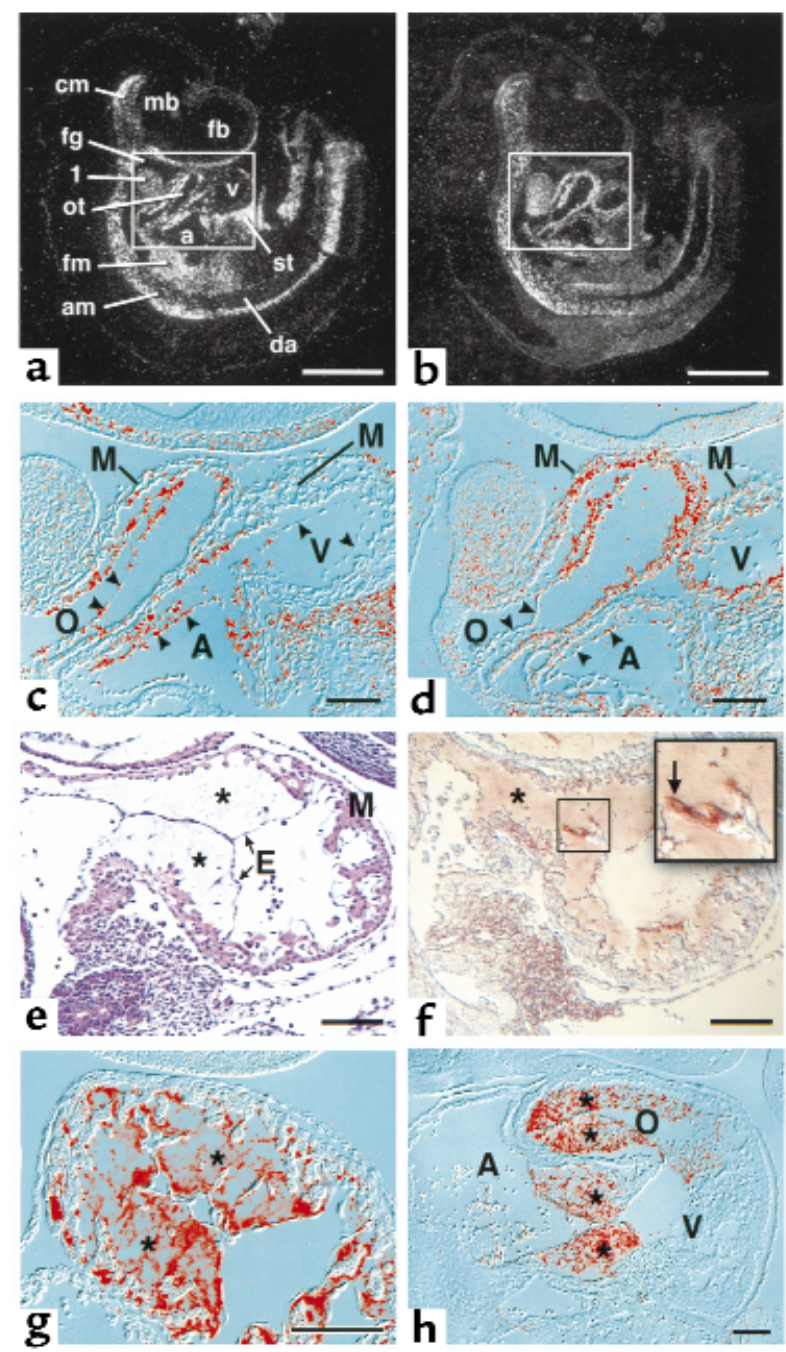

Figure 1

Has2 and versican are expressed in similar domains in the E9.5 mouse. (a) Has2 expression. cm, cranial mesenchyme; fb, forebrain; mb, midbrain; fg, foregut diverticulum; 1 , first branchial arch; ot, outflow tract; $v$, ventricle; a, atrium; st, region of developing septum transversum, including liver primordium and proepicardial organ; fm, foregut mesenchyme; am, periaortic mesenchyme; da, dorsal aorta. (b) Versican expression. (c and d) Higher-power views of the heart region boxed in $\mathbf{a}$ and $\mathbf{b}$, respectively. Has2 and versican mRNAs are expressed in the endothelium (indicated by arrowheads) of the outflow tract $(\mathrm{O})$ and myocardium (M) of the $A V$ canal region. $A$, atrium; $V$, ventricle. (e and $\mathbf{f}$ ) $A V$ canal region and cardiac cushions (indicated by asterisks) of an E9.5 mouse embryo stained with hematoxylin and eosin (e) and for HA using a biotinylated HA-binding protein (f). E, endocardium. The boxed region contains endothelial cells that have transformed and are invading the underlying cushion tissue. These have abundant cell-surface HA (magnified in the inset). (g) Distribution of versican in the $A V$ canal region, superimposing a Nomarski DIC image on a pseudocolored image of versican immunofluorescence. Note that the distribution of versican in $\mathbf{g}$ is similar to the distribution of HA in $\mathbf{f}$. (h) Digital composite image of a Nomarski DIC image and a dark-field image of a ${ }^{35} \mathrm{~S}$-labeled in situ hybridization of Has 2 mRNA in the AV canal and outflow tract region of an E10.5 heart. Mesenchymal cells within the AV canal and outflow tract cushions express abundant Has 2 mRNA. The signal within the atrium results from light scattered by red blood cells, not from silver grains. Bars in $\mathbf{a}$ and $\mathbf{b}=500 \mu \mathrm{m}$; bars in $\mathbf{c}-\mathbf{h}=100 \mu \mathrm{m}$. 


\section{Table 1}

Genotypes of mice resulting from matings of heterozygous $\mathrm{Has}^{+1-}$ mice

\begin{tabular}{lccc}
\hline Genotype: & Has2 $^{+/+}$ & Has2 $^{+/-}$ & Has2 $^{-/-}$ \\
$\begin{array}{l}9.5 \text { days postcoitus }(\mathrm{dpc})^{\mathrm{A}} \\
\begin{array}{l}\text { Observed } \\
\text { Expected }\end{array}\end{array}$ & 50 & 45 & 22 \\
$\begin{array}{l}11.5 \text { days postcoitus } \\
\text { Observed }\end{array}$ & 31 & 62 & 31 \\
$\begin{array}{l}\text { Expected } \\
\text { Live births }\end{array}$ & 14 & 20 & $3^{\mathrm{C}}$ \\
$\begin{array}{l}\text { Observed } \\
\text { Expected }\end{array}$ & 10 & 20 & 10 \\
& 90 & 159 & 0 \\
\end{tabular}

${ }^{A}$ Genotyping of seven embryos in the 9.5-dpc group was inconclusive. ${ }^{\mathrm{B}} \mathrm{A}$ total of 39 embryos were observed in the $11.5 \mathrm{dpc}$ group; genotyping of two embryos undergoing reabsorption was inconclusive. CThe three embryos in this group that were Has $2^{-/-}$were in various stages of decomposition.

Fluorophore-assisted carbobydrate electrophoresis analysis. Glucose, HA, chondroitin sulfate, and dermatan sulfate were quantified by fluorophore-assisted carbohydrate electrophoresis (FACE; Glyko Inc., Novato, California, USA) analysis $(69,70)$. Embryos were digested with $125 \mu \mathrm{g} / \mathrm{mL}$ proteinase $\mathrm{K}$ (GIBCO BRL) in $0.0005 \%$ phenol red and $0.1 \mathrm{M}$ ammonium acetate $(\mathrm{pH} 7.0)$ at $60^{\circ} \mathrm{C}$ for 4 hours. Embryos were then lyophilized, dissolved in the same buffer, and redigested for 4 hours at $37^{\circ} \mathrm{C}$ with $100 \mathrm{mU} / \mathrm{mL}$ each of hyaluronidase SD and chondroitinase ABC (Seikagaku Corp., Tokyo, Japan). 2-aminoacridone $(0.5 \mu \mathrm{M}$; Molecular Probes Inc., Eugene, Oregon, USA) in DMSO and glacial acetic acid $(85: 15)$ was added, and the mixture was incubated for approximately 16 hours at $37^{\circ} \mathrm{C}$. Samples were reduced with $\mathrm{NaCNBr}(50 \mu \mathrm{M})$ (Sigma-Aldrich, St. Louis, Missouri, USA). Fluorescent disaccharides were separated on a MONO composition gel in MONO gel running buffer (Glyko Inc.) for 80 minutes at $500 \mathrm{~V}$, at $4^{\circ} \mathrm{C}$. The gel was imaged at $365 \mathrm{~nm}$ using a cooled CCD camera (Roper Scientific MASD Inc., Tucson, Arizona, USA), and was analyzed using Gel-Pro Analyzer 3.0 software (Media Cybernetics LP, Silver Spring, Maryland, USA). FACE analysis was performed on four individual embryos (two wild-type and two Has $2^{--}$), as well as on pooled wild-type $(n=6)$ and $\operatorname{Has}^{-{ }^{--}}(n=4)$ embryos.

\section{Results}

Has 2 expression during mouse development. Has 2 mRNA is expressed at least from E7.5 through birth in the mouse (6). At day E8.5, Has2 mRNA is localized predominantly in the epithelium of the foregut diverticulum, cephalic mesenchyme, the allantois, and in the myocardium and endocardium of the heart (data not shown). At E9.5, the distribution of Has 2 and versican mRNAs are very similar, with prominent expression in cephalic, foregut, and periaortic mesenchyme; the septum transversum; and the cardiovascular system (Figure $1, a-d)$. Has 2 and versican mRNAs were present in atrial and ventricular endothelium. Versican mRNA was expressed in myocardium as well, whereas Has2
mRNA was less abundant, except in the myocardium of the AV canal region. In the heart at E9.5, cardiac jelly is rich in HA (Figure 1f) and versican (Figure 1g). By E10.5, endothelial cells in the AV canal and outflow tract transform into mesenchymal cells and invade the underlying matrix. The migrating cells express high levels of Has 2 mRNA (Figure 1h) and stain strongly for extracellular HA (Figure 1f, inset). Later, Has2 mRNA is expressed by mesenchymal cells during elevation of the secondary palate and by hypertrophic chondrocytes within epiphysial growth plates (data not shown); this is consistent with a role for Has2dependent HA synthesis in the expansion of soft tissues and in chondrogenesis (24). The relatively high level of expression of Has 2 mRNA and its presence at sites of HA accumulation suggest that Has 2 is a major source of HA during organogenesis.

Targeted inactivation of the Has 2 gene. The replacement vector disrupts the coding sequence of Has2 by inserting a PGK-Neo cassette into the locus (Figure 2). This deleted a portion of intron 3 (including the splice acceptor) and the first 60 codons of exon 4, which encodes part of the cytoplasmic catalytic domain of Has2. The resultant allele encodes a truncated, enzymatically inactive protein. The replacement vector was introduced into the GK129 ES cells (25) and mice by standard methods (26). Mice heterozygous for the targeted allele were fertile and exhibited no obvious abnormalities. Heterozygous intercrosses yielded no viable offspring that were homozygous for the targeted allele $\left(\right.$ Has $\left.^{-/}\right)$, consistent with a lethal embryonic phenotype (Table 1). The first Has2 ${ }^{-/-}$embryos were identified at E11.5, having been partially reabsorbed. Occasional viable embryos were found at E10.5 with beating hearts and significant growth retardation. At day E9.5, the distribution of Has $2^{-/-}$embryos approaches mendelian frequency (Table 1). Analysis of embryonic mRNA by RT-PCR revealed only truncated transcripts of the expected length, with no full-length mRNA expressed in Has $2^{-/-}$embryos (data not shown). Although we have developed anti-peptide antibodies recognizing recombinant Has2 (6), we cannot detect Has 2 protein by immunoblotting extracts of embryonic wild-type mice (data not shown). However, the truncated transcript interrupts the sequence encoding the intracytoplasmic catalytic domain. Thus, any protein product would lack HA synthase activity.

The Has $2^{-/-}$embryos exhibited growth retardation and scant numbers of red blood cells, and lacked vitelline vessels in the yolk sac (Figure 3, a and b). The heart was thinwalled and relatively bloodless, and often exhibited marked pericardial swelling (Figure 3f). The visceral endoderm and mesoderm forming the yolk sac was not fused except at discrete foci (see insets in Figure $3 a$ and $3 \mathrm{~b}$, showing wild-type and Has2 ${ }^{-/-}$sacs, respectively), giving the yolk sac of Has2 ${ }^{-/}$embryos a characteristic punctate appearance (Figure $3 \mathrm{~b}$ ). Red blood cells were present within the space formed by the unfused visceral endoderm and mesoderm (Figure $3 \mathrm{~b}$ ). The hearts of viable 
Has $2^{-/-}$embryos beat with a distinctive to-and-fro motion of red blood cells. This is consistent with absent AV cushions as well as partial or complete obstruction of the outflow tract. Somites were present, albeit distorted, and other structures including the first pharyngeal pouch and otic placodes were also present (Figure 3, c and d). Some of the E9.5 Has $2^{-/-}$embryos had failed to turn, and exhibited posterior defects as well as cephalic mesenchyme abnormalities (data not shown). Wholemount immunostaining for PECAM, a marker for endothelial cells, revealed a marked reduction in vessels in Has2 $2^{-1}$ embryos (compare Figure $3 \mathrm{f}$ with Figure 3e).

Has 2 is required for $H A$ production at $E 9.5$ and for cardiac morphogenesis. Has2 ${ }^{-/-}$embryos have strikingly compacted extracellular space, and do not stain with alcian blue for acidic glycosaminoglycans (Figure 4, a and b). A specific biotinylated probe verified the absence of HA (Figure 4d). Quantitative analysis of pooled embryos using FACE analysis demonstrated a 96\% reduction in HA in Has $2^{-/-}$embryos compared with wild-type littermates
(Table 2). An image of a representative FACE analysis is shown in Figure 5. Wild-type littermates (Figure 5, lanes 2 and 3) clearly yield much higher levels of the fluorescent disaccharide $\triangle \mathrm{DiHA}$ (which is specific to $\mathrm{HA}$ ) than do the Has2 ${ }^{-/-}$embryos (Figure 5, lanes 4 and 5). Other extracellular-matrix components, including collagen I, fibronectin, laminin, and versican were all present in Has $2^{-1}$ embryos. However, their organization was altered in the compacted extracellular spaces (data not shown). The heart lacked cardiac jelly and cushions, although there was a characteristic constriction in the region of the AV canal (Figure 4b, arrows). The myocardium lacked trabeculae even though the ventricular wall was several cell layers thick. These observations confirmed a lack of HA production, compaction of the extracellular space, and lack of endocardial cushions and trabeculae in the hearts of Has2 $2^{-/}$embryos.

Scanning electron microscopy revealed surface and internal detail of the hearts of wild-type and $\mathrm{Has}^{-1-}$ embryos (Figure 6). In the wild-type heart at E9.5, the

\section{a}

129Sv/J mouse Has2 locus
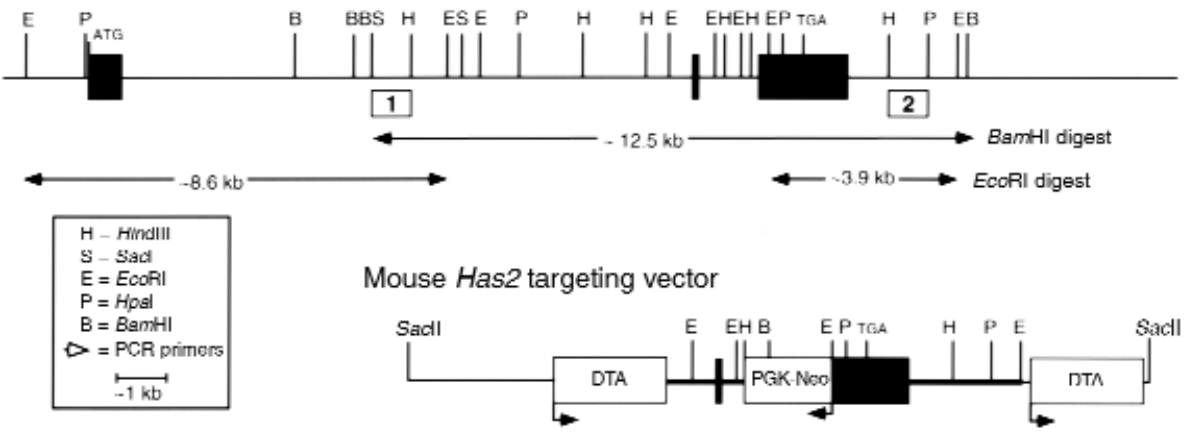

Targeted mouse Has2 locus
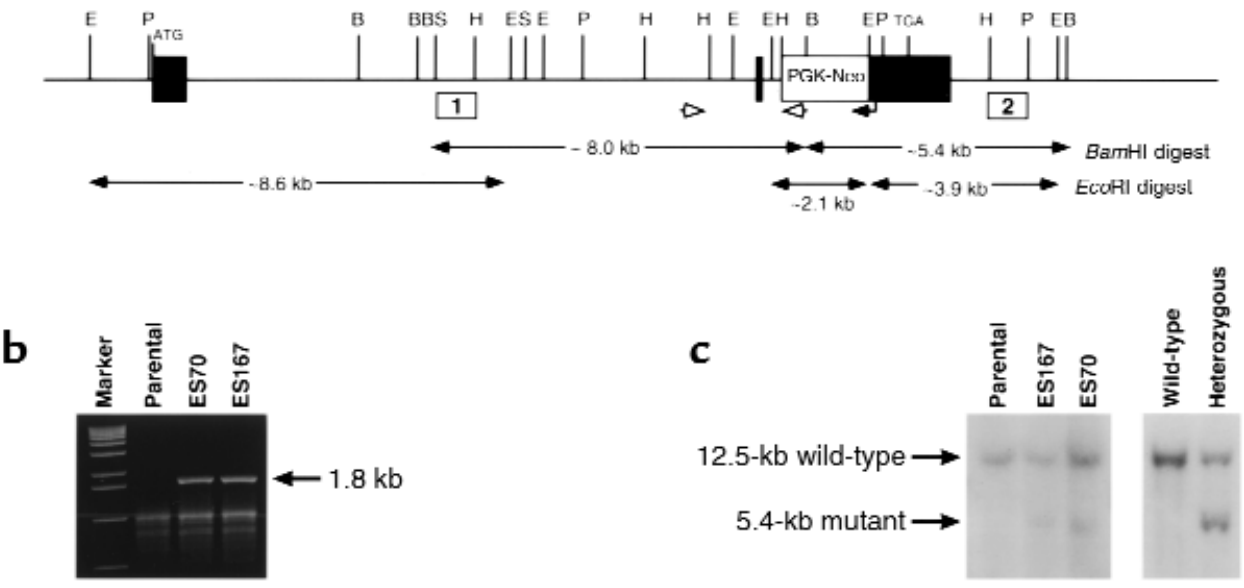

Figure 2

Gene targeting of the Has2 locus. (a) Schematic of a portion of the Has2 locus with restriction sites, exons (filled boxes), the targeting vector, and resulting targeted locus. Homologous recombination replaces the end of intron 3 and the first 60 codons of exon 4 with PGK-Neo. The $\mathrm{BamHI}$ and EcoRI restriction fragments confirming the structure of PCR-positive ES clones are indicated. Arrowheads indicate the direction of transcription of PGK-Neo and the diphtheria toxin A chain. (b) PCR screening with PGK-Neo and flanking primer revealing predicted amplicons of $1.8 \mathrm{~kb}$ in two ES clones. (c) Southern blot analysis of BamHI genomic DNA digests from the parental ES line (control), the two targeted ES clones, a representative wild-type mouse, and a heterozygous mouse. Probe 2 (box 2 in a) detected the 12.5-kb and 5.4-kb restriction fragments corresponding to the wild-type and targeted alleles, respectively. DTA, diphtheria toxin A chain. 

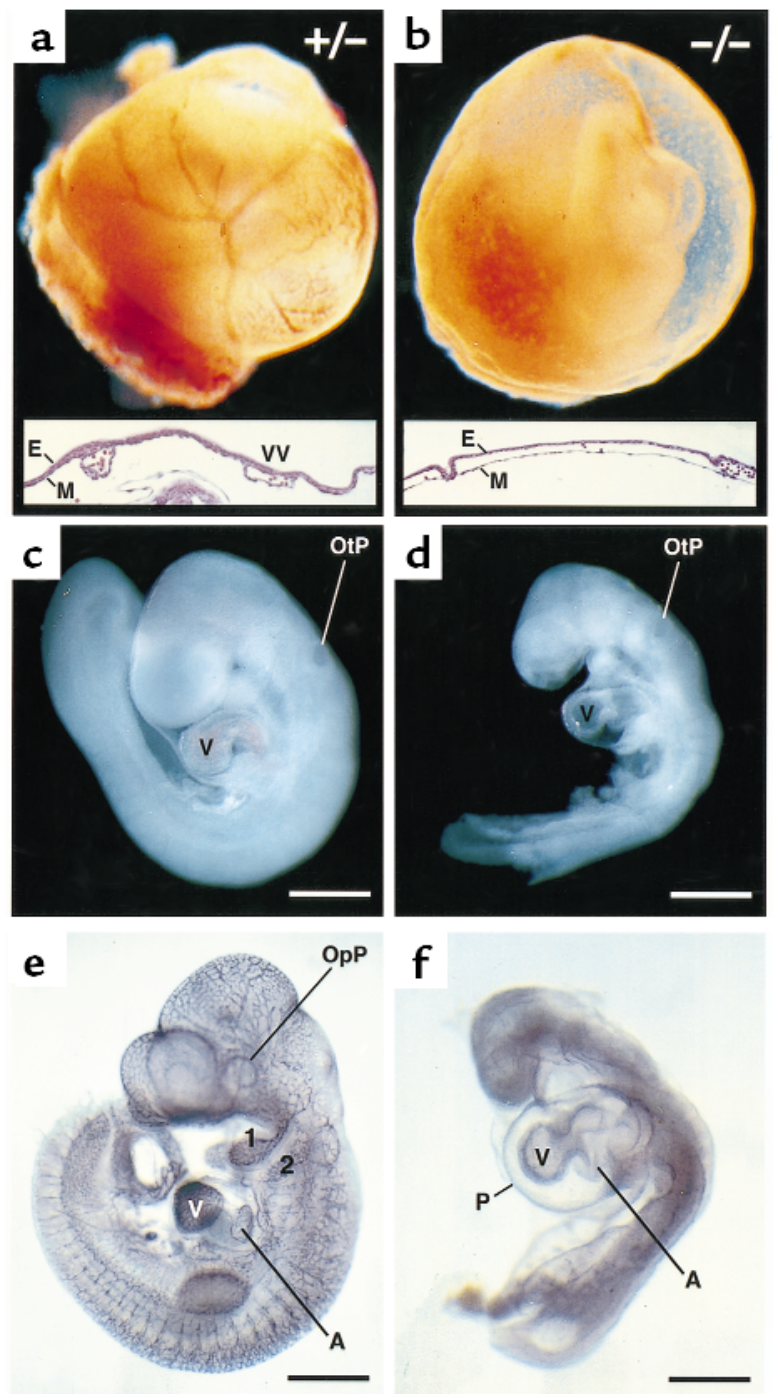

Figure 3

Abnormalities exhibited by Has2 $2^{-/-}$embryos. (a) Yolk sac of an $\mathrm{Has}^{+/-}$ embryo. (b) Yolk sac from an Has2 $2^{-/-}$littermate. Cross-sections of the yolk sac stained with hematoxylin and eosin are shown in the inset. Note the presence of vitelline vessels ( $\mathrm{V}$ ) containing nucleated red blood cells in the yolk sac of the Has $2^{+/-}$embryo. The endoderm and mesoderm are not fused in the Has2 $2^{-/-}$embryo, and the red blood cells are free within this space. (c and d) Representative wild-type and Has2 $2^{--}$embryos at E9.5. Note the diminished size, the bloodless heart, and distorted somites of the Has $2^{-/-}$embryo. (e and f) E9.5 wild-type and Has $2^{-1-}$ embryos stained for the endothelial marker PECAM. Note the absence of an organized vascular network expressing PECAM in the Has $2^{-/-}$embryo. P, pericardium; E, endoderm; M, mesoderm; OpP, optic placode; OtP, otic placode; first and second pharyngeal pouches are numbered. Bars in $\mathbf{c}-\mathbf{f}=500 \mu \mathrm{m}$.

common atrium has moved dorsal and anterior to the ventricle. The left and right ventricles are becoming distinct, and the outflow tract is dividing into the aortic and pulmonary vessels by formation of the aortopulmonary septum (Figure 6b). The heart from an Has2-/embryo has a small atrium, a swollen pericardial space (Figure 6e), and marked reduction of the right ventricle and outflow tract (Figure 6, d-f). The wild-type heart has AV cushions and trabeculation of the ventricle myocardium, whereas the Has $2^{-/}$embryo lacks endocardial cushions and has a compacted ventricle wall devoid of trabeculations (Figure 6, $i$ and $j$ ).

The Has2 $2^{-/-}$phenotype closely resembles that of the bdf mouse (27), which lacks versican, an HA-binding proteoglycan (28). Examination of Has2 and versican mRNAs by in situ hybridization reveals that both are expressed in the heart (Figure 1, a-d). Moreover, the cardiac jelly is rich in HA and versican (Figure 1, $\mathrm{f}$ and $\mathrm{g})$. Thus, the common phenotype resulting from disruption of the Has 2 and versican genes demonstrates that both matrix molecules are essential for formation of cardiac jelly and endocardial cushions.

Transformation of cardiac endothelium to mesenchyme does not occur in the absence of Has 2 and is restored by adding exogenous HA or by expressing Has 2 cDNA. At 4-5 weeks gestation in the human, and by E9-10 in the mouse, the cardiac jelly expands rapidly in the AV canal and outflow tract, forming the cardiac cushions. Initially, the AV cushions function as valves ensuring unidirectional blood flow. Then, a subset of endothelial cells lining the cushions detaches from adjacent cells, migrates, and transforms into mesenchymal cells that invade and remodel the cushions into the tricuspid and mitral valves and the membranous portion of the interventricular septum. This process requires soluble signals released from the underlying myocardium interacting with receptor tyrosine kinases in the endothelium $(29,30)$. We could not assess AV canal formation in situ because of the absence of cushions in Has2 ${ }^{-/}$embryos. However, in vitro collagen gels support endothelium-to-mesenchyme transformation of $\mathrm{AV}$ canal explants, duplicating the in situ events in AV canal morphogenesis. This system has been extensively validated and used to elucidate the signals regulating $\mathrm{AV}$ canal development (30-33). In vitro, this process is characterized by migration of endothelial (endocardial) cells as an epithelial sheet, followed by retraction and separation of the endothelium ("activation"). Finally, the activated endothelial cells undergo transformation, invading the underlying collagen gel and expressing a repertoire of mesenchymal genes de novo, such as $\alpha$-smooth muscle actin. For clarity, we will refer to the entire process as AV canal morphogenesis, and will refer to each step with the terms "endothelial migration," "activation," and "transformation." It is important to

Table 2

FACE analysis of $\triangle \mathrm{DiHA}$ content of wild-type and Has2 ${ }^{-/-}$embryos

\section{Genotype}

$\triangle \mathrm{DiHA}^{\mathrm{A}}$

Wild-type \#1

Wild-type \#9

Pooled wild-type $(n=6)$

Pooled Has2 $2^{-1}(n=4)$

Has $2^{-1-}$ \#6A

Has2 ${ }^{-1-}$ \#7A

219,000

191,000

253,333

8,311

22,961

${ }^{A}$ Relative fluorescence units. ND, not detected. 


\section{Figure 4}

E9.5 Has2 $2^{-/-}$embryos lack alcian blue-staining glycosaminoglycans and HA in cardiac jelly. The cardiac jelly of wild-type embryos is rich in acidic glycosaminoglycans (blue stain in a) and HA (brown stain in c). In contrast, Has $2^{-/}$embryos totally lack alcian blue-stained material (b) and HA (d). The heart of the Has $2^{-/-}$embryo has a characteristic constriction at the AV canal region (indicated by the arrows), but no endocardial cushions, which are indicated by the asterisks in a and $\mathbf{c}$. Bars in a and $\mathbf{b}=100 \mu \mathrm{m}$; bars in $\mathbf{c}$ and $\mathbf{d}=250 \mu \mathrm{m}$.
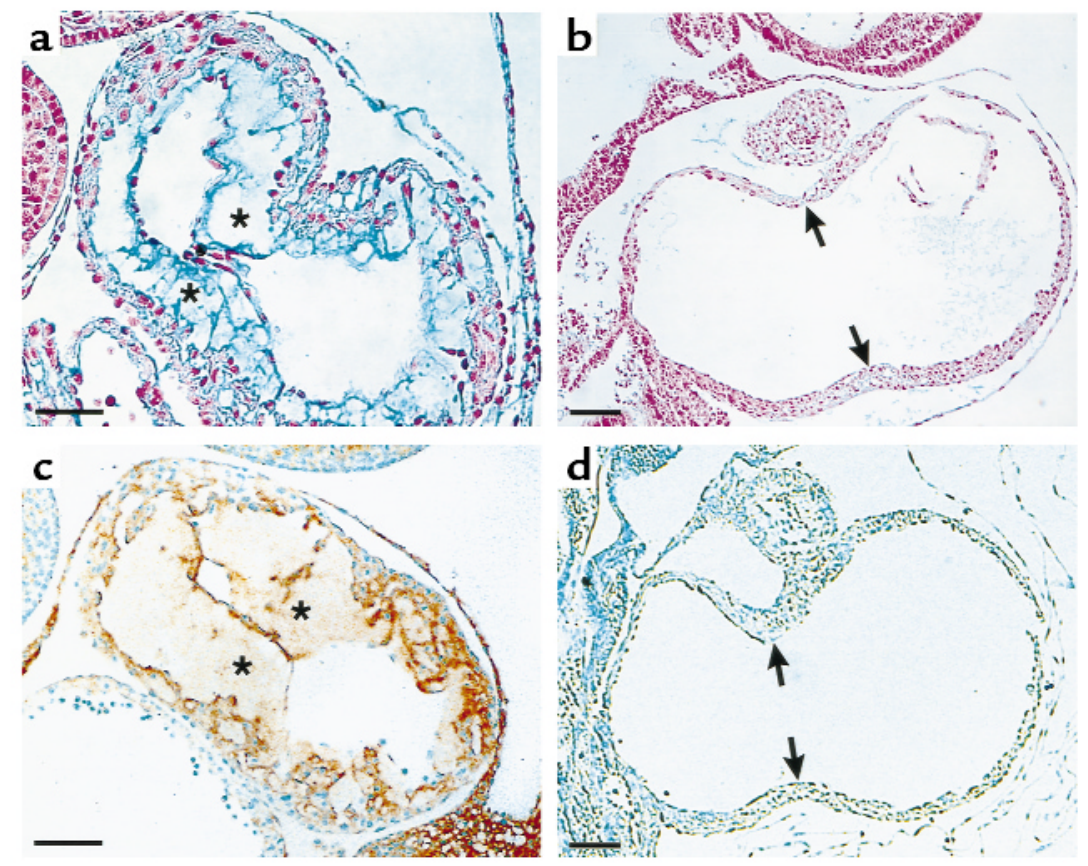

recognize that most published studies of in vitro $\mathrm{AV}$ canal morphogenesis use the chick. In the mouse, we find that formation of a distinct endothelial sheet occurs only in AV canal explants from embryos at E10-10.5. We studied E9.5 embryos to avoid artifacts associated with the morbidity of the Has2 $2^{-/}$embryo. At this age, a definitive endothelial sheet is rarely seen (Camenisch et al., unpublished results).

In AV canal explants from E9.5 wild-type embryos, numerous endothelial cells migrated over the surface of the collagen gel, transformed, and invaded the gel matrix (Figure 7, a and b). The mesenchymal cells expressed characteristic mesenchymal markers, including fibulin-1 and fibulin-2 (data not shown) $(34,35)$. In contrast, endothelial-cell migration was absent in AV canal explants from Has2 $2^{-/}$embryos (Figure $7 \mathrm{~d})$. The production of diffusible signaling molecules by the myocardium $(33,36,37)$ and the responsiveness of the endothelial cells to signals are temporally and spatially regulated (29). Either (or both) could be deficient in Has $2^{-/}$embryos. However, if migration or transformation were lacking solely due to the absence of HA, then providing exogenous HA or restoring Has2 function should correct the defect. To test this, we transfected Has $2^{-/}$explants with Has2 cDNA. An empty control vector had no effect on migration or transformation in Has2 $2^{-/-}$explants (Figure $7 \mathrm{~d}$ ), whereas transfection with Has2 cDNA restored both migration and transformation (Figure $7 \mathrm{e})$. Moreover, supplementing the culture medium (Figure 7f) or the collagen gel with HA (Figure 7g) also restored the normal phenotypic response in $\mathrm{Has}^{-1-} \mathrm{AV}$ explants. Interestingly, exogenous HA was fully effective at $\mathrm{ng} / \mathrm{mL}$ concentrations, implicating a high-avidity interaction mediating its biological effects (data not shown). (Boiling the HA had no effect on its ability to restore AV canal morphogenesis in vitro.) Finally, conditioned medium from AV explant cultures from wild-type embryos also restored migration, epithelium-to-mesenchyme transformation, and invasion in Has2 $2^{--} \mathrm{AV}$ explants (data not shown). The transforming activity was abrogated by treatment with

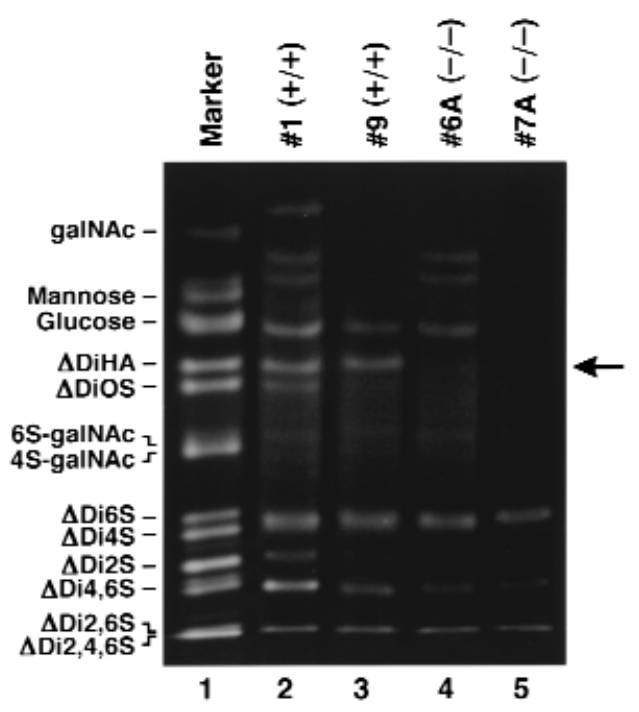

Figure 5

FACE analysis of E9.5 embryo extracts for HA. Lane 1 contains disaccharide standards. Lanes 2-5 represent $5 \%$ of a single embryo (lanes 2 and 3 are wild-type; lanes 4 and 5 are Has $\left.2^{--}\right)$. The arrow indicates the $\triangle \mathrm{DiHA}$ disaccharide derived from $\mathrm{HA}$. Note the marked reduction of the $\triangle \mathrm{DiHA}$ band in the individual Has $2^{-/}$samples compared with wild-type controls. Additional analyses of material pooled from wild-type or Has2 $2^{--}$embryos and run at higher concentrations (equivalent to $40-60 \%$ of a single embryo) gave similar results (data not shown; see Table 1). 


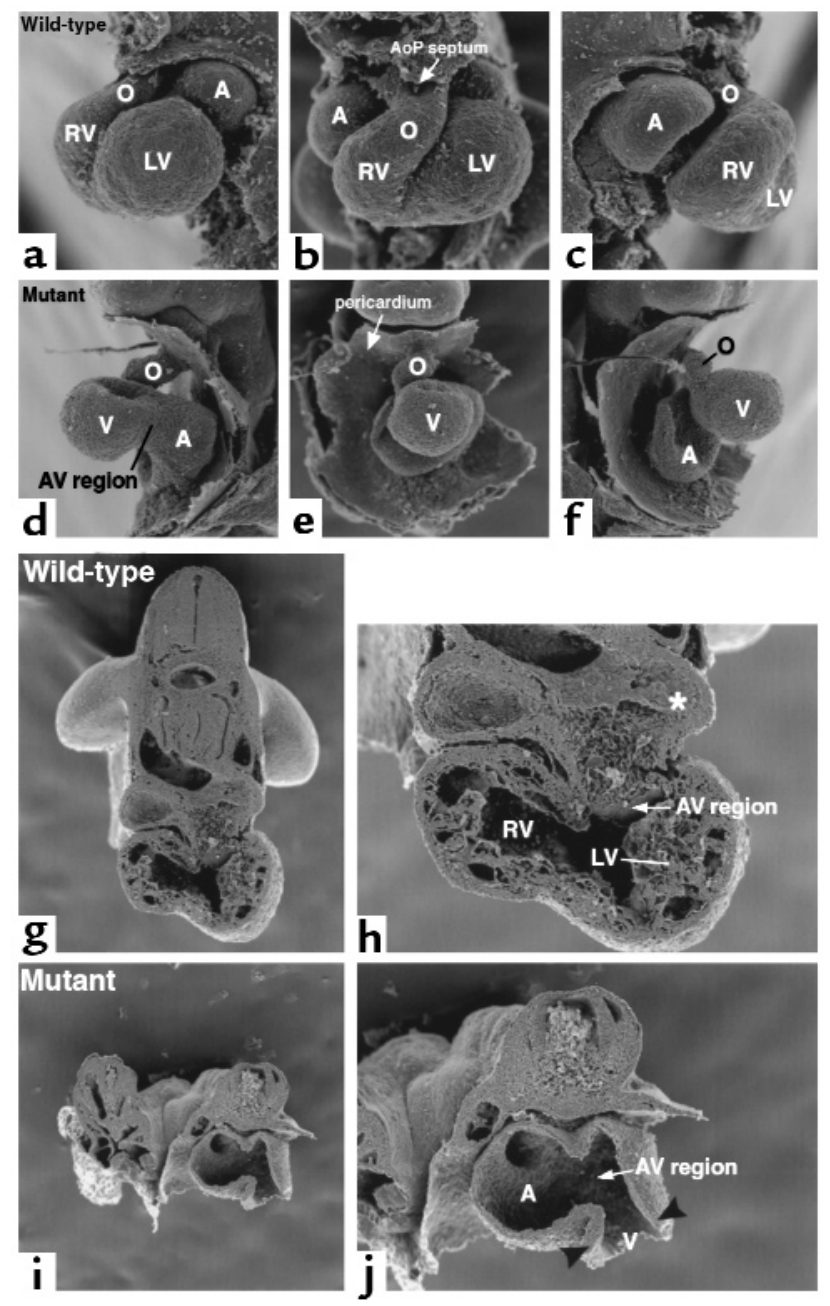

Figure 6

Ultrastructure of wild-type and Has2-/- E9.5 mouse hearts. Scanning electron micrograph of the external structure of the heart from a wildtype (a-c) and an Has $2^{-/}$embryo (d-f). Specimens were viewed from the left side ( $\mathbf{a}$ and $\mathbf{d}$ ), the front ( $\mathbf{b}$ and $\mathbf{e}$ ), and the right side ( $\mathbf{c}$ and $\mathbf{f}$ ). Note the apparent absence of the presumptive right ventricle and outflow tract in the Has $2^{-1-}$ embryo compared with the wild type. Scanning electron microscopy of cross-sections of hearts from wild-type ( $\mathbf{g}$ and $\mathbf{h}$ ) and $\mathrm{Has}^{-/-}$embryos (i and $\mathbf{j}$ ) reveal a lack of AV cushions and a compacted ventricle wall lacking trabeculations (arrowheads). There is a constriction at the site of the AV canal in the Has $2^{-/-}$embryo. LV, left ventricle; RV, right ventricle; AoP septum, aortic pulmonary septum. Asterisks indicate left posterior atrial wall. $\mathbf{h}$ and $\mathbf{j}$ are higher magnifications of $\mathbf{g}$ and $\mathbf{i}$, respectively.

hyaluronidase (data not shown). The rescue of endothelial migration and transformation in $\mathrm{AV}$ explant cultures from Has $2^{--}$hearts demonstrates that neither the production of defined transforming activity by the myocardium (i.e., TGF- $\beta$ ) nor endothelial-cell competence is deficient in Has $2^{-/-}$embryos. The simplest interpretation is that HA is required for migration and possibly for subsequent transformation of the endothelial-cell population into mesenchyme. Notably, AV canal endothelial migration, transformation, and invasion is not affected in versican-deficient $h d f$ mice, despite their lack of cardiac jelly (27).
The requirement for $\mathrm{HA}$ in $\mathrm{AV}$ canal morphogenesis is removed by expressing constitutively active Ras, and HA-mediated AV canal morphogenesis in vitro requires Ras. Unregulated Ras activity leads to hyperproliferation of mesenchymal cells and AV cushion defects (30). We assessed the effect of expressing dominant-negative Ras in AV canal explants. Dominant-negative Ras significantly reduced the migration and transformation of endothelial cells in wild-type AV canal explant cultures, mimicking the Has2 $2^{-/}$phenotype (Figure $7 \mathrm{c}$ ). Thus, a pathway acting through Ras is important for transformation and invasion by cardiac endothelium. Next, we tested whether expressing constitutively active Ras could negate the requirement for $\mathrm{HA}$ in $\mathrm{AV}$ canal morphogenesis in explants from Has2 $/ /$ embryos. Active Ras restored the normal phenotypic response in Has2 $2^{-/}$ $\mathrm{AV}$ explants to wild-type levels (Figure 7h). Thus, expression of activated Ras circumvents the requirement for HA in migration and epithelium-to-mesenchyme transformation. Finally, to determine if exogenous HA is acting via pathways involving Ras activation, we assessed the effect of inhibiting Ras on migration and transformation in Has2 $2^{-/}$explants treated with HA. As shown in Figure 8, dominant-negative Ras significantly inhibited transformation mediated by $\mathrm{HA}$ in $\mathrm{Has}^{-/-}$ explants. The endothelial cells adopted an epithelial phenotype and migrated over the collagen gel, but did not transform into mesenchyme or invade the collagen gel. This result suggests that a pathway requiring HA and leading to Ras activation is essential for endothelial transformation during $\mathrm{AV}$ canal morphogenesis. Endothelial migration, although dependent upon HA, occurs irrespective of Ras activity.

\section{Discussion}

Has2 is the major source of HA during embryogenesis, and $H A$ is essential in cardiac organogenesis. The lethality in Has $2^{-/}$embryos underscores the critical role of HA in cardiovascular morphogenesis and demonstrates that Has2 is the major source of HA during this period of embryonic development. A functional cardiovascular system is required to sustain life beyond E9.5-10 (38). HA appears at E5.5 in the yolk cavity, and by E6.5 is present in all embryonic cavities, the embryonic and extraembryonic mesoderm, and the allantois $(16,17)$. Either another Has gene (i.e., Has1 or Has3) must function earlier in development to replace Has2 function, or HA is dispensable before cardiac morphogenesis; this is currently being evaluated. Phenotypically, we cannot distinguish $\mathrm{Has}^{-/}$embryos earlier than approximately E8.5. Targeting of the other Has genes has been accomplished, and $\mathrm{Has}^{1^{-/-}}$and $\mathrm{Has}^{-/-}$animals are viable and fertile (unpublished data). Furthermore, compound Has 1 , Has 3 homozygous-null mice are viable and fertile, underscoring the pivotal role of Has2 during embryogenesis. We are currently creating $\mathrm{Has}^{1^{-/}}$, $\mathrm{Has}^{+/-}$, Has $3^{-/-}$animals to assess whether haploinsufficiency occurs with only one functional Has2 allele. 
There are profound defects in vasculogenesis in the Has $2^{-/-}$embryos involving the yolk sac and systemic vasculature. Similar abnormalities are seen in the yolk sacs of mice lacking molecules that mediate cell-matrix and cell-cell interactions, including $\alpha 5$-integrin (39) and Ncadherin (40). Interestingly, yolk sac pathology is seen in mice that lack N-Ras function and are heterozygous for a null mutation in $K$-ras (41). These abnormalities can also be associated with pericardial edema (38), but we believe that the vascular abnormalities result from the absence of HA, because despite near-identical cardiac phenotypes, $h d f$ mice do not have yolk sac defects (Corey Mjaatvedt, personal communication). The early lethality of $\mathrm{Has}^{-/-}$embryos makes it difficult to directly assess the role of Has2 in the development of other embryonic structures. This will require more sophisti-
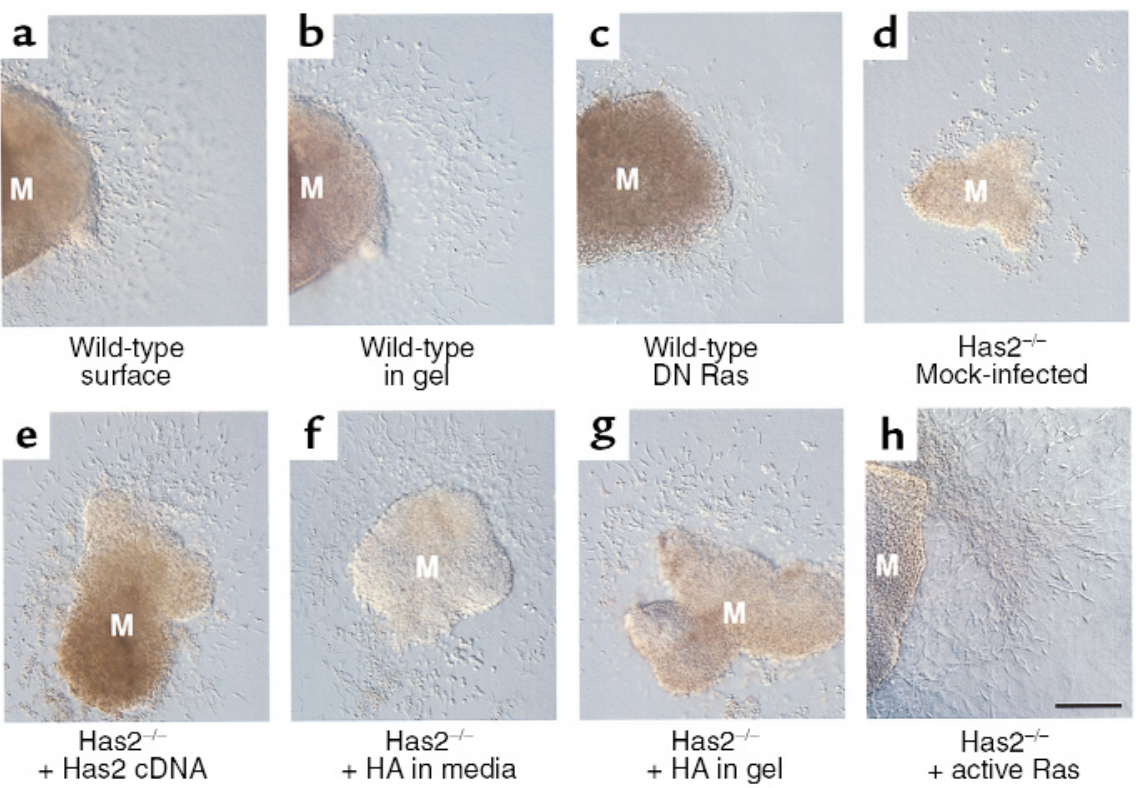

Has2 $^{-/-}$

Mock-infected
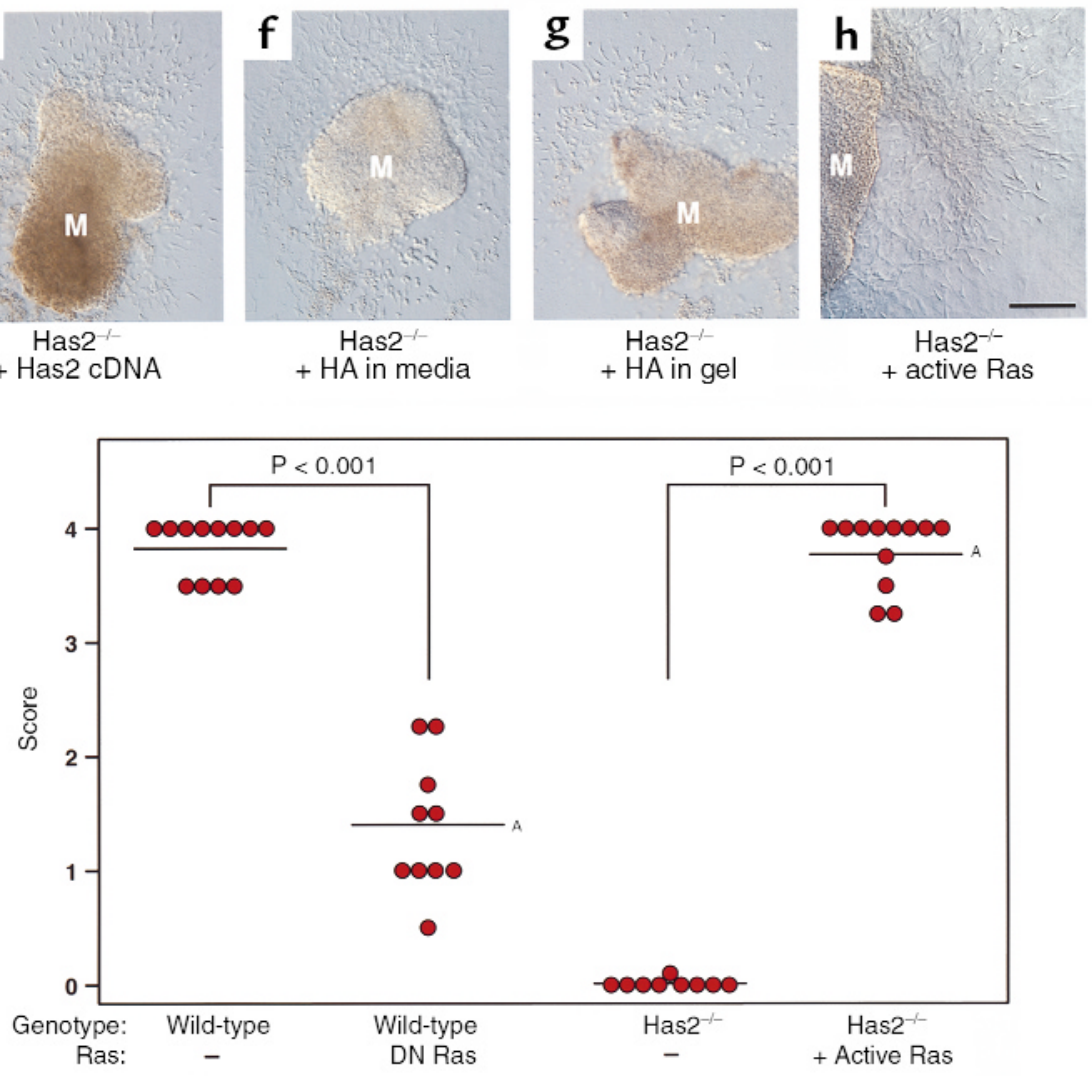

\section{Figure 7}

AV canal morphogenesis is deficient in Has $2^{-/-}$AV canal explants and is restored by exogenous HA or activated Ras. Top panel: AV canal explant morphogenesis in vitro. AV canal explants from E9.5 wild-type (a-c) or Has $2^{-/-}$embryos $(\mathbf{d}-\mathbf{h})$ were cultured on collagen gels. Explants from wild-type embryos exhibit abundant endothelial cell migration and invasion (image $\mathbf{a}$ is focused on the surface of the gel; $\mathbf{b}$ is focused below the surface). In contrast, there is no endothelial-cell migration in AV canal explants from E9.5 Has2-/- embryos (d). Transfection with dominant-negative $(\mathrm{DN})$ Ras cDNA significantly $(P<0.001)$ reduces endothelial migration and invasion in AV explants from wild-type embryos $(\mathbf{c})$. Because migration and invasion begins during the 16-hour incubation before transfection, the degree of inhibition is probably underestimated (see Methods). AV canal explants from Has $2^{-/}$embryos exhibit comparable morphogenesis after transfection with Has 2 cDNA (e), in the presence of HA in the media (f), or in the collagen gel ( $\mathbf{g}$ ). Transformation in Has $2^{-/-}$embryos is also rescued by transfecting with constitutively active Ras (h). M, myocardium. Nomarski DIC optics. Bar in $\mathbf{h}=200 \mu \mathrm{m}$. Bottom panel: Quantification of AV canal transformation in the presence or absence of either dominant-negative Ras $(\mathrm{S} 17 \mathrm{~N})$ or constitutively active Ras (Q61L). The dominant-negative Ras significantly inhibited cell migration and invasion in viable wild-type explants, whereas constitutively active Ras restored cell migration and invasion in AV explants from Has $2^{-/-}$embryos to the same degree as wild-type explants. The scoring method is outlined in Methods. ${ }^{A} P<0.001$. 


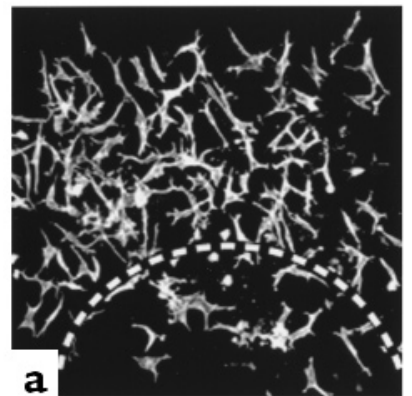

HA alone

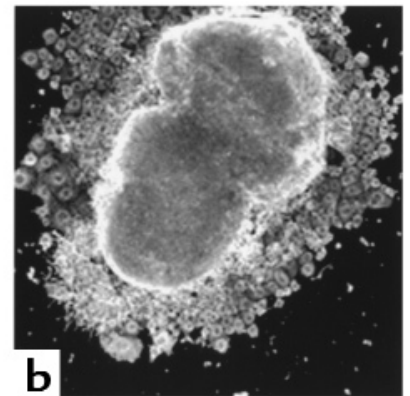

$\mathrm{HA}+\mathrm{DN}$ Ras

\section{Figure 8}

Dominant-negative Ras inhibits HA-mediated endothelial-cell invasion in Has2 $2^{--}$AV canal explants. These images were obtained by laser scanning confocal microscopy after staining for $\alpha$-smooth muscle actin. Exogenous HA $(0.75 \mathrm{mg} / \mathrm{mL}$ of medium) was added to the culture medium in both Has $2^{-1-}$ explants. (a) A collapsed Z series of $100 \mu \mathrm{m}$ showing the characteristic transformation to mesenchyme and invasion of the collagen gel in the presence of exogenous HA. The dotted line indicates the previous location of the myocardium, which was removed. (b) Characteristic effect of transfection with dominant-negative Ras. In contrast to the rescued AV explant, an epithelial sheet has migrated over the surface of the collagen gel, but there are no invading mesenchymal cells. Similar results were obtained in three independent experiments.

cated in vivo genetic approaches, such as generation of chimeric animals or tetraploid rescue.

A composite matrix is required for expansion of the extracellular space during cardiac cushion formation. Abnormal formation of the endocardial cushions results in AV septal defects, the second most common cardiac defect in infants (42). The similar phenotype of HA-deficient Has $2^{--}$and versican-deficient $h d f$ mice reveals for the first time the critical importance of a composite matrix containing $\mathrm{HA}$ in $\mathrm{AV}$ canal morphogenesis. Clearly, neither molecule alone is sufficient for this process. HA interacts with other matrix molecules, including inter$\alpha$-trypsin inhibitor (43), link protein (44), and fibulins (45). Fibulin is present in cardiac cushions (34), and binds both HA and versican (45). These interactions, in conjunction with our observations, underscore the diversity and potential importance of composite matrices in the development of the AV cushions. The expression of endocardial cushion matrix components in the AV canal is probably controlled by activity of upstream transcription factors implicated in cardiac morphogenesis. Potential candidates include the basic HLH transcription factor Hand2, which is required for proper morphogenesis of the right ventricle and outflow tract/conus $(46,47)$, and epicardin, another basic HLH transcription factor (48). We are currently analyzing the Has2 gene locus for regulatory elements that are responsible for Has2 expression in the developing heart.

$H A$ is required for endothelial-cell migration and transformation in AV canal morphogenesis. A striking and unexpected outcome of our studies is the requirement for HA in cell migration, transformation, and subsequent invasion. Whereas previous studies have implicated HA in cardiac

development $(31,49,50)$, our investigation demonstrates an absolute requirement for $\mathrm{HA}$ during $\mathrm{AV}$ canal morphogenesis in vivo and in vitro. This is the first report of a developmental system in which cell migration and transformation have an absolute dependence on HA. The fact that dominant-negative Ras inhibits endothelial cell migration and transformation in normal $\mathrm{AV}$ explants confirms the requirement for Ras activity during AV morphogenesis (30). Moreover, constitutively active Ras circumvents the requirement for HA in endothelial-cell transformation in $\mathrm{Has}^{-/-}$embryo explants. Finally, we show that the ability of HA to rescue normal endothelial transformation to mesenchyme in $\operatorname{Has}^{2--} \mathrm{AV}$ canals is inhibited by dominant-negative Ras. This indicates that the HA induction converges on Ras activation during transformation of these cardiac endothelial cells. Interestingly, treatment of $\mathrm{Has}^{-/-} \mathrm{AV}$ explants with HA in the presence of dominant-negative Ras supports endothelial cell migration, but not transformation (Figure 8). Therefore, endothelial cell migration is independent of active Ras signaling, but is still dependent on HA. Therefore, two sequential steps require HA: migration of endothelial cells, which may not require Ras, followed by their transformation into mesenchyme, which appears to require Ras signaling.

What is the mechanism through which HA acts? One possibility is that HA binding to a cognate receptor, e.g., CD44, activates downstream pathways that converge on Ras activation. Although CD44-deficient mice are not reported to exhibit any cardiovascular phenotype (51), we have observed retarded endothelial-cell transformation in vitro with $\mathrm{AV}$ explants from $\mathrm{CD} 44^{-/-}$embryos (data not shown), as well as partial inhibition of transformation using a monoclonal antibody blocking CD44-HA binding (52). Additionally, HA may serve as a costimulatory molecule acting in concert with known receptor-mediated signaling pathways. This is a well accepted paradigm for integrin matrix receptors, which act synergistically with growth factor receptors (53-56). Given the ubiquitous distribution of HA in cardiac jelly and the sharply restricted domain of endothelial-cell transformation, we favor the latter hypothesis. Provocatively, mice with null mutations in either an ErbB ligand, heregulin-1 (neuregulin-1), or in the cognate receptors ErbB3 and ErbB4 exhibit cardiac phenotypes resembling those of the Has $2^{--}$and $h d f$ embryos (57-59). Heregulin-1 is expressed in AV canal endothelial cells; ErbB3 is expressed in the subjacent AV canal mesenchyme (57). Binding of HA to CD44 activates Ras cooperatively with members of the receptor tyrosine kinase ErbB family $(21,60)$, and HA activates mitogenactivated protein kinase via Ras (61). HA binding to CD44 also activates Rac1 and promotes formation of lamellipodia in mouse epithelial cells (62). Collectively, these observations suggest that an HA-dependent, receptor-mediated signaling event involving $\mathrm{HA}, \mathrm{CD} 44$, and ErbB receptors/ligands may be essential for $\mathrm{AV}$ canal morphogenesis. Collectively, our data indicate that $\mathrm{HA}$ acts by stimulating intracellular signaling path- 
ways, including Ras, and that additional or alternative receptors for HA may compensate for CD44.

Our results demonstrate that HA plays two distinct and complementary roles during $\mathrm{AV}$ canal morphogenesis. First, HA is a necessary component of the extracellular supramolecular array expanding the extracellular matrix, a requisite for formation of cardiac jelly and the endocardial cushions. Second, although the cognate receptor (or receptors) must be defined, HA acting in concert with additional factors stimulates the Ras-dependent intracellular signaling that is necessary for endothelial cell transformation to form mesenchymalized cushions. These observations reveal a novel mechanism in which an extracellular matrix component, HA, acts through a receptor complex to induce Ras-dependent signaling and cell transformation. It remains to be seen whether HA plays similar, dual roles in the development of other embryonic structures and in tumor progression by expanding the extracellular space and inducing cell migration and transformation.

\section{Acknowledgments}

Marv Ruona and Julie Jensen provided graphics support. Judy Bradley, Suresh Savarirayan, and the transgenic core staff assisted with transgenics, and M. Anita Jennings provided histology services. We would also like to acknowledge helpful discussions with Ray Runyan, Joyce A. Schroeder, and Maria Valencik. Vincent Hascall and Maria Benavides at the Cleveland Clinic assisted with the FACE analysis. This work was supported by NIH grants 1RO1 AR-44689 and T32 HL07897, the Desert Mountain Affiliate of the American Heart Association, and the Mayo Foundation for Medical Education and Research.

1.Philipson, L.H., Westley, J., and Schwartz, N.B. 1985. Effect of hyaluronidase treatment of intact cells on hyaluronate synthetase activity. Biochemistry. 24:7899-7906.

2. Ng, K.F., and Schwartz, N.B. 1989. Solubilization and partial purification of hyaluronate synthetase from oligodendroglioma cells. J. Biol. Chem. 264:11776-11783.

3. Watanabe, K., and Yamaguchi, Y. 1996. Molecular identification of a putative human hyaluronan synthase. J. Biol. Chem. 271:22945-22948.

4. Itano, N., and Kimata, K. 1996. Expression cloning and molecular characterization of HAS protein, a eukaryotic hyaluronan synthase. J. Biol. Chem. 271:9875-9878.

5. Shyjan, A.M., Heldin, P., Butcher, E.C., Yoshino, T., and Briskin, M.J. 1996. Functional cloning of the cDNA for a human hyaluronan synthase. J. Biol. Chem. 271:23395-23399.

6. Spicer, A.P., and McDonald, J.A. 1998. Characterization and molecular evolution of a vertebrate hyaluronan synthase gene family. J. Biol. Chem. 273:1923-1932.

7. Spicer, A.P., et al. 1997. Chromosomal localization of the human and mouse hyaluronan synthase genes. Genomics. 41:493-497.

8. Spicer, A.P., Olson, J., and McDonald, J.A. 1997. Molecular cloning of a gene encoding a third mammalian hyaluronan synthase, Has3. J. Biol. Chem. 272:8957-8961.

9. Spicer, A.P., Augustine, M.L., and McDonald, J.A. 1996. Molecular cloning and characterization of a putative mouse hyaluronan synthase. J. Biol. Chem. 271:23400-23406.

10. Itano, N., et al. 1999. Three isoforms of mammalian hyaluronan synthases have distinct enzymatic properties. J. Biol. Chem. 274:25085-25092.

11. Scott, J.E., and Heatley, F. 1999. Hyaluronan forms specific stable tertiary structures in aqueous solution: a 13C NMR study. Proc. Natl. Acad. Sci. USA. 96:4850-4855.

12. Haddon, C.M., and Lewis, J.H. 1991. Hyaluronan as a propellant for epithelial movement: the development of semicircular canals in the inner ear of Xenopus. Development. 112:541-550.

13. Camaioni, A., Salustri, A., Yanagishita, M., and Hascall, V.C. 1996. Proteoglycans and proteins in the extracellular matrix of mouse cumulus cell-oocyte complexes. Arch. Biochem. Biophys. 325:190-198.

14. Tirone, E., D’Alessandris, C., Hascall, V.C., Siracusa, G., and Salustri, A. 1997. Hyaluronan synthesis by mouse cumulus cells is regulated by interactions between follicle-stimulating hormone (or epidermal growth factor) and a soluble oocyte factor (or transforming growth factor beta1). J. Biol. Chem. 272:4787-4794.

15. Kohda, D., et al. 1996. Solution structure of the link module: a hyaluronan-binding domain involved in extracellular matrix stability and cell migration. Cell. 86:767-775.

16. Brown, J.J., and Papaioannou, V.E. 1993. Ontogeny of hyaluronan secretion during early mouse development. Development. 117:483-492.

17. Fenderson, B.A., Stamenkovic, I., and Aruffo, A. 1993. Localization of hyaluronan in mouse embryos during implantation, gastrulation and organogenesis. Differentiation. 54:85-98.

18. Watanabe, H., et al. 1994. Mouse cartilage matrix deficiency ( $\mathrm{cmd}$ ) caused by a 7 bp deletion in the aggrecan gene. Nat. Genet. 7:154-157.

19. Kosaki, R., Watanabe, K., and Yamaguchi, Y. 1999. Overproduction of hyaluronan by expression of the hyaluronan synthase Has 2 enhances anchorage-independent growth and tumorigenicity. Cancer Res. 59:1141-1145.

20. Itano, N., Sawai, T., Miyaishi, O., and Kimata, K. 1999. Relationship between hyaluronan production and metastatic potential of mouse mammary carcinoma cells. Cancer Res. 59:2499-2504

21. Bourguignon, L.Y., et al. 1997. Interaction between the adhesion receptor, CD44, and the oncogene product, p185HER2, promotes human ovarian tumor cell activation. J. Biol. Chem. 272:27913-27918.

22. Banerji, S., et al. 1999. LYVE-1, a new homologue of the CD44 glycoprotein, is a lymph-specific receptor for hyaluronan. J. Cell Biol. 144:789-801.

23. McKee, C.M., et al. 1997. Hyaluronan fragments induce nitric-oxide synthase in murine macrophages through a nuclear factor kappaB-dependent mechanism. J. Biol. Chem. 272:8013-8018.

24. Nishida, Y., Knudson, C.B., Nietfeld, J.J., Margulis, A., and Knudson, W. 1999. Antisense inhibition of hyaluronan synthase-2 in human articular chondrocytes inhibits proteoglycan retention and matrix assembly. J. Biol. Chem. 274:21893-21899.

25. Philpott, K.L., et al. 1992. Lymphoid development in mice congenitally lacking $\mathrm{T}$ cell receptor alpha beta-expressing cells. Science. 256:1448-1452.

26. George, E.L., and Hynes, R.O. 1994. Gene targeting and generation of mutant mice for studies of cell-extracellular matrix interactions. Methods Enzymol. 245:386-420.

27. Yamamura, H., Zhang, M., Markwald, R.R., and Mjaatvedt, C.H. 1997. A heart segmental defect in the anterior-posterior axis of a transgenic mutant mouse. Dev. Biol. 186:58-72.

28. Mjaatvedt, C.H., Yamamura, H., Capehart, A.A., Turner, D., and Markwald, R.R. 1998. The Cspg2 gene, disrupted in the hdf mutant, is required for right cardiac chamber and endocardial cushion formation. Dev. Biol. 202:56-66.

29. Eisenberg, L.M., and Markwald, R.R. 1995. Molecular regulation of atrioventricular valvuloseptal morphogenesis. Circ. Res. 77:1-6.

30. Lakkis, M.M., and Epstein, J.A. 1998. Neurofibromin modulation of ras activity is required for normal endocardial-mesenchymal transformation in the developing heart. Development. 125:4359-4367.

31. Bernanke, D.H., and Markwald, R.R. 1979. Effects of hyaluronic acid on cardiac cushion tissue cells in collagen matrix cultures. Tex. Rep. Biol. Med. 39:271-285.

32. Runyan, R.B., and Markwald, R.R. 1983. Invasion of mesenchyme into three-dimensional collagen gels: a regional and temporal analysis of interaction in embryonic heart tissue. Dev. Biol. 95:108-114.

33. Brown, C.B., Boyer, A.S., Runyan, R.B., and Barnett, J.V. 1999. Requirement of type III TGF-beta receptor for endocardial cell transformation in the heart. Science. 283:2080-2082.

34. Bouchey, D., Argraves, W.S., and Little, C.D. 1996. Fibulin-1, vitronectin, and fibronectin expression during avian cardiac valve and septa development. Anat. Rec. 244:540-551.

35. Miosge, N., Sasaki, T., Chu, M.L., Herken, R., and Timpl, R. 1998. Ultrastructural localization of microfibrillar fibulin-1 and fibulin-2 during heart development indicates a switch in molecular associations. Cell. Mol. Life. Sci. 54:606-613.

36. Boyer, A.S., et al. 1999. TGFbeta2 and TGFbeta3 have separate and sequential activities during epithelial-mesenchymal cell transformation in the embryonic heart. Dev. Biol. 208:530-545.

37. Boyer, A.S., Erickson, C.P., and Runyan, R.B. 1999. Epithelial-mesenchymal transformation in the embryonic heart is mediated through distinct pertussis toxin-sensitive and TGFbeta signal transduction mechanisms. Dev. Dyn. 214:81-91.

38. Copp, A.J. 1995. Death before birth: clues from gene knockouts and mutations. Trends Genet. 11:87-93. 
39. Yang, J.T., Rayburn, H., and Hynes, R.O. 1993. Embryonic mesodermal defects in alpha 5 integrin-deficient mice. Development. 119:1093-1105.

40. Radice, G.L., et al. 1997. Developmental defects in mouse embryos lacking N-cadherin. Dev. Biol. 181:64-78.

41. Johnson, L., et al. 1997. K-ras is an essential gene in the mouse with partial functional overlap with N-ras [erratum 1997, 11:3277]. Genes Dev. 11:2468-2481.

42. Rubin, E.M., Ishida, B.Y., Clift, S.M., and Krauss, R.M. 1991. Expression of human apolipoprotein A-I in transgenic mice results in reduced plasma levels of murine apolipoprotein A-I and the appearance of two new high density lipoprotein size subclasses. Proc. Natl. Acad. Sci. USA. 88:434-438.

43. Bost, F., Diarra-Mehrpour, M., and Martin, J.P. 1998. Inter-alpha-trypsin inhibitor proteoglycan family: a group of proteins binding and stabilizing the extracellular matrix. Eur. J. Biochem. 252:339-346.

44. Binette, F., Cravens, J., Kahoussi, B., Haudenschild, D.R., and Goetinck, P.F. 1994. Link protein is ubiquitously expressed in non-cartilaginous tissues where it enhances and stabilizes the interaction of proteoglycans with hyaluronic acid. J. Biol. Chem. 269:19116-19122.

45. Aspberg, A., Adam, S., Kostka, G., Timpl, R., and Heinegard, D. 1999. Fibulin-1 is a ligand for the C-type lectin domains of aggrecan and versican. J. Biol. Chem. 274:20444-20449.

46. Thomas, T., Yamagishi, H., Overbeek, P.A., Olson, E.N., and Srivastava, D. 1998. The bHLH factors, dHAND and eHAND, specify pulmonary and systemic cardiac ventricles independent of left-right sidedness. Dev. Biol. 196:228-236.

47. Srivastava, D., et al. 1997. Regulation of cardiac mesodermal and neural crest development by the bHLH transcription factor, dHAND [erratum 1997, 16:410]. Nat. Genet. 16:154-160.

48. Robb, L., et al. 1998. Epicardin: a novel basic helix-loop-helix transcription factor gene expressed in epicardium, branchial arch myoblasts, and mesenchyme of developing lung, gut, kidney, and gonads. Dev. Dyn. 213:105-113.

49. Krug, E.L., Runyan, R.B., and Markwald, R.R. 1985. Protein extracts from early embryonic hearts initiate cardiac endothelial cytodifferentiation. Dev. Biol. 112:414-426.

50. Baldwin, H.S., Lloyd, T.R., and Solursh, M. 1994. Hyaluronate degradation affects ventricular function of the early postlooped embryonic rat heart in situ. Circ. Res. 74:244-252.

51. Schmits, R., et al. 1997. CD44 regulates hematopoietic progenitor distribution, granuloma formation, and tumorigenicity. Blood. 90:2217-2233.

52. Miyake, K., Underhill, C.B., Lesley, J., and Kincade, P.W. 1990. Hyaluronate can function as a cell adhesion molecule and CD44 participates in hyaluronate recognition. J. Exp. Med. 172:69-75.

53. Rosales, C., O'Brien, V., Kornberg, L., and Juliano, R. 1995. Signal transduction by cell adhesion receptors. Biochim. Biophys. Acta. 1242:77-98.

54. Lin, T.H., Chen, Q., Howe, A., and Juliano, R.L. 1997. Cell anchorage permits efficient signal transduction between ras and its downstream kinases. J. Biol. Chem. 272:8849-8852.
55. Howe, A.K., and Juliano, R.L. 1998. Distinct mechanisms mediate the initial and sustained phases of integrin-mediated activation of the Raf/MEK/mitogen-activated protein kinase cascade. J. Biol. Chem. 273:27268-27274

56. Schwartz, M.A., and Baron, V. 1999. Interactions between mitogenic stimuli, or, a thousand and one connections. Curr. Opin. Cell Biol. 11:197-202.

57. Meyer, D., and Birchmeier, C. 1995. Multiple essential functions of neuregulin in development [erratum 1995, 378:753]. Nature. 378:386-390.

58. Erickson, S.L., et al. 1997. ErbB3 is required for normal cerebellar and cardiac development: a comparison with ErbB2-and heregulin-deficient mice. Development. 124:4999-5011.

59. Gassmann, M., et al. 1995. Aberrant neural and cardiac development in mice lacking the ErbB4 neuregulin receptor. Nature. 378:390-394.

60. Ilangumaran, S., Briol, A., and Hoessli, D.C. 1998. CD44 selectively associates with active Src family protein tyrosine kinases Lck and Fyn in glycosphingolipid-rich plasma membrane domains of human peripheral blood lymphocytes. Blood. 91:3901-3908.

61. Serbulea, M., et al. 1999. Hyaluronan activates mitogen-activated protein kinase via Ras-signaling pathway. Int. J. Oncol. 14:733-738.

62. Oliferenko, S., Kaverina, I., Small, J.V., and Huber, L.A. 2000. Hyaluronic acid (HA) binding to CD44 activates Rac1 and induces lamellipodia outgrowth. J. Cell. Biol. 148:1159-1164.

63. Broekelmann, TJ, Limper, A.H. Colby, TV and McDonald, J.A. 1991. Transforming growth factor beta 1 is present at sites of extracellular matrix gene expression in human pulmonary fibrosis. Proc. Natl. Acad. Sci. USA. 88:6642-6646.

64. Baraniuk, J.N., Shizari, T., Sabol, M., Ali, M., and Underhill, C.B. 1996. Hyaluronan is exocytosed from serous, but not mucous cells, of human nasal and tracheobronchial submucosal glands. J. Invest. Med. 44:47-52.

65. Seo, J.W., Kim, E.K., Brown, N.A., and Wessels, A. 1995. Section directed cryosectioning of specimens for scanning electron microscopy: a new method to study cardiac development. Microsc. Res. Tech. 30:491-495.

66. Spicer, A.P., Rowse, G.J., Lidner, T.K., and Gendler, S.J. 1995. Delayed mammary tumor progression in Muc-1 null mice. J. Biol. Chem. 270:30093-30101.

67. van den Hoff, M.J., et al. 1999. Myocardialization of the cardiac outflow tract. Dev. Biol. 212:477-490.

68. Allgood, V.E., Zhang, Y., O’Malley, B.W., and Weigel, N.L. 1997. Analysis of chicken progesterone receptor function and phosphorylation using an adenovirus-mediated procedure for high-efficiency DNA transfer. Biochemistry. 36:224-232.

69. Calabro, A., Hascall, V.C., and Midura, R.J. 2000. Adaptation of FACE methodology for microanalysis of total hyaluronan and chondroitin sulfate composition from cartilage. Glycobiology. 10:283-293.

70. Calabro, A., Benavides, M., Tammi, M., Hascall, V.C., and Midura, R.J. 2000. Microanalysis of enzyme digests of hyaluronan and chondroitin/dermatan sulfate by fluorophore-assisted carbohydrate electrophoresis (FACE). Glycobiology. 10:273-281. 